\title{
Skin Manifestations of Hepatitis C in Chronic Renal Disease Patients
}

\author{
Awad Magbri* \\ MD, Dialysis Access Center of Pittsburgh, PA
}

Received: October 21, 2016; Accepted: May 4, 2017; Published: May 16, 2017

*Corresponding author: Awad Magbri, MD, Dialysis Access Center of Pittsburgh, PA. E-mail: elmagbri@hotmail.com

\begin{abstract}
Hepatitis C infection is a major cause of acute and chronic hepatitis. Health care workers and high risk behaviors are at increased risk of infection. The incidence of a new cases of hepatitis $\mathrm{C}$ has sharply decreased in the United States, but the prevalence remained high (2.7 M) American infected with the virus. Chronic infection is progressive disease and results in severe morbidity in $20-30 \%$ of infected persons. Cutaneous manifestations (extra-hepatic) of hepatitis $\mathrm{C}$ infection are found in $20-40 \%$. Kidneys and skin are the main organs involved after the liver. This mini-review highlights the common skin manifestation of the virus.
\end{abstract}

Key words: Hepatitis C Infection; Extra-Hepatic Manifestation; Essential Cryoglobulinemia; Lichen Planus; Porphyria Cutanea Tarda; Vasculitis.

\section{Background}

Hepatitis $C$ virus is a single stranded RNA virus. It is a major cause of acute and chronic hepatitis. The mode of infection is usually through intravenous drug abuse or transfusion of infected blood or blood products. Heath care workers are at risk for needle stick and other with high-risk sexual behavior is also considered a major risk factor for HCV infection. The incidence of new cases of acute HCV infection has sharply decreased in the United States during the past decade, but the prevalence remains high with approximately 2.7 million Americans infected with the virus. Chronic HCV infection progresses in roughly $75 \%$ of patients after acute infection by the virus. Chronic HCV infection is slowly progressive disease and results in severe morbidity in $20-30 \%$ of infected persons.

Cutaneous manifestations of chronic HCV infection are found in $20-40 \%$ of patients and are often presented to the dermatologists for treatment. The extra-hepatic manifestations of the virus are numerous and the kidneys and skin are the most organs involved after the liver [1].

The extra-hepatic manifestations of chronic hepatitis C infection are many, including [1-4]:

-Hematological diseases such as cryoglobulinemia and lymphoma [2]

-Autoimmune disorders such as thyroiditis

\section{-Renal disease}

-Dermatological diseases such as lichen planus, porphyria cutanea tarda, skin lymphoma, and vasculitis $[3,4]$.

In this mini-review will try to shed light on the skin manifestation of HCV infection in patients with chronic HCV infection. It is recognized that most extrahepatic manifestation of HCV infection are common in chronic kidney disease and can occur in $38 \%$ of patients [3].

Essential cryoglobulinemia or (type II mixed cryoglobulinemia), is a lymphoproliferative disorder which leads to deposition of circulating immune complexes in small to medium sized blood vessels. This type of disorder is common with chronic HCV infection. The most common clinical manifestation of this disease includes palpable purpura, arthralgia and renal disease (in the form of membranoproliferative glomerulonephritis, or membranous nephropathy) with hypocomplementemia.

Skin involvement is often associated with neurological manifestation in the form of peripheral neuropathy due to involvement of the small blood vessels in the peripheral nerves. The purpuric vasculitis in the lower extremities may undergo necrosis and ulceration. Digital necrosis and skin lymphoma may also occur. More than $90 \%$ of patients with essential cryoglobulinemia are infected with HCV and patients should undergo evaluation for HCV infection [5].

Skin vasculitis and cryoglobulin levels may respond to treatment of HCV infection. Plasmapheresis, steroids, cytotoxics, and specific anti-HCV medications are the mainstay therapy of HCV infection in this condition.

The association of HCV infection with monoclonal gammopathies has been inconsistent. In one study 35\% are positive for HCV in patients with smoldering or multiple myeloma [6]. The incidence of monoclonal gammopathies increased in the age group of $60-69$ years (21\%). 50\% of these patients are infected with HCV genotype $2 \mathrm{a} / \mathrm{c}$. In another study $12 \%$ of HCV positive patients had a monoclonal gammopathies compared to $3 \%$ of the control group [7]. HCV infection has been associated with polyclonal or oligoclonal hyperglobulinemia (most often IgG) $[8,9]$. The kidneys are often involved in monoclonal gamopathy that is known collectively as (monoclonal gamopathy of renal 
significance). This disease can present with asymptomatic proteinuria, hematuria or decline in renal function. Kidney biopsies along with urine and serum free light chain estimation are almost always diagnostic.

B-cell Non-Hodgkin's Lymphoma (NHL) has been associated with HCV infection and renal involvement by the lymphoma is not uncommon. Patients with renal involvement can present with hematuria, proteinuria, or acute kidney injury with decline in renal function. Direct lymphomatous infiltration of the kidney can also occur. This type of lymphoma is usually diffuse large B-cell lymphoma. However, marginal zone lymphoma, splenic and mucosa-associated lymphoma have been reported to occur [10-20]. If the NHL involved the skin it can present with raised violaceous areas of the skin and intense pruritus. Lymphoma may develop due to progression of cryoglobulinemia [19-23]. Chronic stimulation of the immune system by HCV infection can lead to progression of lymphoproliferative disorder. The immune system react to continuous stimulation of HCV-E2 protein with increased prevalence of chromosomal translocation, $\mathrm{t}(14: 18)$ in the B cell-lineage [24-27].

Treatments of HCV infections with antiviral therapy along with chemotherapy for the underlying lymphoma are used in these cases. In this review will highlight the most common cutaneous manifestation of chronic hepatitis C infection with emphases on the common skin manifestations.

\section{Skin manifestations of chronic HCV infection}

\section{Porphyria cutanea tarda}

Leukocytoclastic vasculitis including (Polyarteritis nodosa, erythema nodosum, erythema multiforme)

Lichen planus

Necrolytic acral erythema

Cutaneous lymphoma

\section{Porphyria Cutanea Tarda (PCT)}

PCT develops in patients with risk factors like exposure to chemical or toxic agents, drugs, iron overload, or excessive alcohol intake [28,29]. PCT is manifested as blisters, vesicles on the dorsal parts of the acral sufaces, especially the dorsum of the hands. Minor trauma and sun exposure can lead to erythema and the development of vesicles and bullae. Hypo or hyper pigmentation, hirsutism, and sclerodermatous changes may develop. Hypertrichosis of the temples, pigmented changes, scarring, ulcerations, and dystrophic calcifications can occur. These lesions are the results of skin fragility with symptoms of epidermolysis bullosa. Uroporphyrins and hepatocarboxyl porphyrins collect in skin, bones, and teeth after they spell into the blood once the liver is saturated. These pigments can fluorescent on light exposure and turn the urine dark red upon urination.

In the United States the prevalence of HCV infection in patients with PCT is estimated at 50\% [30]. PCT is caused by reduced activity of the enzyme uroporphyrinogen decarboxylase, causing build-up of uroporphyrinogen in the blood and urine [31]. PCT can be inherited also as autosomal dominant form which has the same characteristics as the acquired form. The skin and the liver are the two main organs affected by the disease. Chronic liver disease with steatosis, fibrosis, and cirrhotic changes are the next common manifestation that may occur [32].

Alcohol, estrogen, iron overload and the exposure to hydrocarbons are among the triggering factors. Simultaneous, HCV infection of liver and kidney may occur. Diagnosis of PCT is typically suspected on clinical grounds and confirmed by marked elevation of urine uroporphyrin levels. The disease can also be confirmed directly by measuring hepatic uroporphyrinogen decarboxylase activity. All patients with PCT should be evaluated for HCV infection; HIV and iron overload e.g. hemochromatosis (with HFE mutation testing). Treatment of PCT consists of avoiding the precipitating factors, treating iron overload, and HCV infection.

\section{Leukocytoclastic Vasculitis (LV)}

Leukocytoclastic vasculitis presented as palpable purpura, petechiae, ulceration of the skin, livido reticularis, polyarthritis and myalgia [33]. Leukocytoclastic vasculitis usually involves the lower extremities. Skin biopsy showed cutaneous vasculitis with dermal blood vessel destruction and infiltration of neutrophils around the vessel walls. Peripheral nerves may also be involved resulting in peripheral neuropathy secondary to involvement of the small vessels supplying the nerves, vasa vasorum [34].

Leukocytoclastic vasculitis is associated with essential mixed cryoglobulinemia, poly arteritis nodosa, erythema nodosum, and erythema multiforme. The kidneys are usually involved in essential cryoglobulinemia with membranoproliferative glomerulonephritis, membranous glomerulonephritis, and hypertension with reduced kidney function. Polyarteritis nodosa is another disease of the small or medium sized blood vessels which is related to HBV and HCV infection that can involve many organs including the kidneys. Polyarteritis nodosa is found in approximately $10 \%$ of HBV and HCV infection. Kidney function can be stabilized with the sustained viral response of HCV infection to the new antiviral medications. Complete disappearance of arthralgia, skin, and liver diseases occurred with clearance of HCV infection, suggesting that urticarial vasculitis may result from HCV immune complex disease.

\section{Lichen Planus (LP)}

Lichen planus is a skin disorder characterized by flattopped, violaceous, and pruritic papules with scaly base. The distribution of the lesions of LP is generalized that can involve mucus membranes, hair lines, and nails. The mechanism of pathogenesis of LP is not known but cell mediated immunity may play a major role [35].

Skin biopsy usually showed dense lymphocytic infiltration in the upper dermis. It is estimated that $10-40 \%$ of patients with LP are positive for HCV infection [36]. It is believed 
that LP may be exacerbated by interferon treatment for HCV. The effect of new anti HCV drugs is not known. Sustained viral response may alleviate the symptoms of LP.

\section{Necrolytic Acral Erythema}

It is a necrolysis erythematous skin lesion on the acral parts of the body. It is characterized by pruritic, psoriasis-like skin disease on sharply marginated, erythematous base with hyper pigmented plaques and variable scales which can be confused with LP or psoriasis. In a series of 30 patients with the disorder, all were found to have antibodies to HCV [37]. Skin biopsy usually shows psoriatic changes, necrosis of the keratinocytes, and papillomatosis. These patients may have kidney involvement in the form of proteinuria or decreased kidney function. Treatment of HCV and topical steroids with oral zinc supplements may alleviate the disease [38-41].

\section{Cutaneous Lymphoma}

Cutaneous lymphoma is mainly T-cell lymphoma which has no relation to HCV infection. However, diffuse B-cell lymphoma can involve the skin and subcutaneous tissue with palpable masses that may ulcerate to the skin surface. These cases may be associated with HCV infection. The differential diagnosis of cutaneous lymphoma should be considered in LP, psoriasis, or ulceration of the skin.

\section{Treatment of HCV Infection}

Treatment of HCV infection is a rapidly evolving field; guidelines by the American Association for the Study of Liver Disease have been updated in 2015 and 2016. The treatment depends on the genotype of the virus and the organ involved.

The general treatment recommendations include:

-determination of HCV genotype and subtype including quantitative HCV load,

-complete blood count, liver function tests, and renal function tests,

-Evaluation of advanced liver fibrosis with liver biopsy, imaging, and /or invasive markers.

-It is recommended that treatment should be carried out by healthcare provider who is expert in HCV infection.

-Treatment of skin manifestation of HCV infection should be coordinated with HCV specialist.

\section{References}

1. Sterling RK, Bralow S. Extrahepatic manifestations of hepatitis $C$ virus. Curr Gastroenterol Rep. 2006;8(1):53-59.

2. Metts J, Carmichael L, Kokor W, Scharffenberg R. Hepatitis C: extrahepatic manifestations. FF Essent. 2014;427:32-35.

3. Fachinelli LR, Silva EC, Figueiredo MG, Possa MS, Pelegrinelli FF, Molina RJ. Hepatitis C and Cutaneous alterations. Rev Soc Bras Med Trop. 2012;45(6):770-773.

4. Akhter A, Said A. Cutaneous manifestations of viral hepatitis. Curr
Infect Dis Rep. 2015;17(2):452. doi: 10.1007/s11908-014-0452-7

5. Lunel F, Musset L, Cacoub P, Frangeul L, Cresta P, Perrin M, et al. Cryoglobulinemia in chronic liver diseases: role of hepatitis $C$ virus and liver damage. Gastroenterology. 1994;106(5):1291-1300.

6. Andreone P, Zignego AL, Cursaro C, Gramenzi A, Gherlinzoni F, Fiorino $\mathrm{S}$, et al. Prevalence of monoclonal gammopathies in patients with hepatitis C virus infection. Ann Intern Med. 1998;129(4):294-298.

7. Perrone A1, Deramo MT, Spaccavento F, Santarcangelo P, Favoino B, Antonaci S. Hepatitis C virus (HCV) genotypes, human leucocyte antigen expression and monoclonal gamopathy prevalence during chronic HCV infection. Cytobios. 2001;106 Suppl 1:125-134.

8. Tsianos EV, Di Bisceglie AM, Papadopoulos NM, Costello R, Hoofnagle $\mathrm{JH}$. Oligoclonal immunoglobulin bands in serum in association with chronic viral hepatitis. Am J Gastroenterol. 1990;85(8):1005-1008.

9. Maruyama S1, Hirayama C, Horie Y, Yorozu K, Maeda K, Inoue M, et al. Serum immunoglobulins in patients with chronic hepatitis C: a surrogate marker of disease severity and treatment outcome. Hepatogastroenterology. 2007;54(74):493-498.

10. Gisbert JP, Garcia-Buey L, Pajares JM, Moreno-Otero R. Prevalence of hepatitis $\mathrm{C}$ virus infection in B-cell non-Hodgkin's lymphoma: systemic review and meta-analysis. Gastroenterology. 2003;125(6):1723-1732.

11. Giordano TP, Henderson L, Landgren O, Chiao EY, Kramer JR, El-Serag $\mathrm{H}$, et al. Risk of non-Hodgkin lymphoma and lymphoproliferative precursor disease in US veterans with hepatitis C virus. JAMA. 2007;297(18):2010-2017.

12. de Sanjose S, Benavente Y, Vajdic CM, Engels EA, Morton LM, Bracci PM, et al. Hepatitis C and non-Hodgkin lymphoma among 4784 cases and 6269 controls from the International Lymphoma Epidemiology Consortium. Clin Gastroenterol Hepatol. 2008;6(4):451-458. doi: 10.1016/j.cgh.2008.02.011

13. Silvestri F, Pipan C, Barillari G, Zaja F, Fanin R, Infanti L, et al. Prevalence of hepatitis $\mathrm{C}$ virus infection in patients with lymphoproliferative disorders. Blood. 1996;87(10):4296-4301.

14. Monti G, Pioltelli P, Saccardo F, Campanini M, Candela M, Invernizzi $\mathrm{F}$, et al. Incidence and characteristics of non-Hodgkin lymphomas in a multicenter case file of patients with hepatitis C virusrelated symptomatic mixed cryoglobulinemias. Arch Intern Med. 2005;165(1):101-105. doi:10.1001/archinte.165.1.101

15. Bronowicki JP, Bineau C, Feugier P, Hermine O, Brousse N, Oberti F, et al. Primary lymphoma of the liver: clinical-pathological features and relationship with HCV infection in French patients. Hepatology. 2003;37(4):781-787. doi: 10.1053/jhep.2003.50121

16. Luppi M, Longo G, Ferrari MG, Ferrara L, Marasca R, Barozzi P, et al. Additional neoplasms and HCV infection in low-grade lymphoma of MALT type. Br J Haematol. 1996;94(2):373-375.

17. De Vita S, De Re V, Sansonno D, Sorrentino D, Corte RL, Pivetta B, et al. Gastric mucosa as an additional extrahepatic localization of hepatitis C virus: viral detection in gastric low-grade lymphoma associated with autoimmune disease and in chronic gastritis. Hepatology. 2000;31(1):182-189. doi: 10.1002/hep.510310127

18. Tursi A, Brandimante G, Chiarelli F, Spagnoli A, Torello M. Detection of HCV RNA in gastric mucosa-associated lymphoma tissue by in situ 
hybridization: evidence of a new extrahepatic localization of HCV with increased risk of gastric malt lymphoma. Am J Gastroenterol. 2002;97(7):1802-1806. doi: 10.1111/j.1572-0241.2002.05848.x

19. Rasul I, Shepherd FA, Kamel-Reid S, Krajden M, Pantalony D, Heathcote EJ. Detection of occult low-grade B-cell non-Hodgkin's lymphoma in patients with chronic hepatitis $\mathrm{C}$ infection and mixed cryoglobulinemia. Hepatology. 1999;29(2):543-547. doi: 10.1002/hep.510290224

20. Hermine 0 , Lefrère F, Bronowicki JP, Mariette X, Jondeau K, EclacheSaudreau V. Regression of splenic lymphoma with villous lymphocytes after treatment of hepatitis $\mathrm{C}$ virus infection. $\mathrm{N}$ Engl J Med. 2002;347(2):89-94. doi: 10.1056/NEJMoa013376

21.Ennishi D, Maeda Y, Niitsu N, Kojima M, Izutsu K, Takizawa J. Hepatic toxicity and prognosis in hepatitis $\mathrm{C}$ virus-infected patients with diffuse large B-cell lymphoma treated with rituximab-containing chemotherapy regimens: a Japanese multicenter analysis. Blood. 2010;116(24):5119-5125. doi: 10.1182/blood-2010-06-289231

22. Quinn ER, Chan CH, Hadlock KG, Foung SK, Flint M, Levy S. The B-cell receptor of a hepatitis C virus (HCV)-associated non-Hodgkin lymphoma binds the viral E2 envelope protein, implicating HCV in lymphomagenesis. Blood. 2001;98(13):3745-3749.

23. Pozzato G, Mazzaro C, Crovatto M, Modolo ML, Ceselli S, Mazzi G, et al. Low-grade malignant lymphoma, hepatitis $C$ virus infection, and mixed cryoglobulinemia. Blood. 1994;84(9):3047-3053.

24.Zignego AL, Giannelli F, Marrocchi ME, Mazzocca A, Ferri C, Giannini C, et al. T $(14 ; 18)$ translocation in chronic hepatitis $C$ virus infection. Hepatology. 2000;31(2):474-479. doi: 10.1002/hep.510310230

25. Kitay-Cohen Y, Amiel A, Hilzenrat N, Buskila D, Ashur Y, Fejgin M, et al. Bcl-2 rearrangement in patients with chronic hepatitis $\mathrm{C}$ associated with essential mixed cryoglobulinemia type II. Blood. 2000;96(8):2910-2912.

26.Zuckerman E, Zuckerman T, Sahar D, Streichman S, Attias D, Sabo E, et al. bcl-2 and immunoglobulin gene rearrangement in patients with hepatitis C virus infection. Br J Haematol. 2001;112(2):364-369.

27.Zignego AL, Ferri C, Giannelli F, Giannini C, Caini P, Monti M, et al. Prevalence of bcl-2 rearrangement in patients with hepatitis $\mathrm{C}$ virusrelated mixed cryoglobulinemia with or without B-cell lymphomas. Ann Intern Med. 2002;137(7):571-580.

28. Bulaj ZJ, Phillips JD, Ajioka RS, Franklin MR, Griffen LM, Guinee DJ, et al. Hemochromatosis genes and other factors contributing to the pathogenesis of porphyria cutanea tarda. Blood. 2000;95(5):15651571.

29. Cribier B, Petiau P, Keller F, Schmitt C, Vetter D, Heid E, et al. Porphyria Cutanea Tarda and Hepatitis C Viral Infection. A Clinical and Virologic
Study. Arch Dermatol. 1995;131(7):801-804.

30. Gisbert JP, Garcia-Buey L, Pajares JM, Moreno-Otero R. Prevalence of hepatitis $\mathrm{C}$ virus infection in porphyria cutanea tarda: systematic review and meta-analysis. J Hepatol. 2003;39(4):620-627.

31. Kushner JP, Barbuto AJ, Lee GR. An inherited enzymatic defect in porphyria cutanea tarda: decreased uroporphyrinogen decarboxylase activity. J Clin Invest. 1976;58(5):1089-1097. doi: 10.1172/JCI108560

32. Di Padova C, Marchesi L, Cainelli T, Gori G, Podenzani SA, Rovagnati $P$, et al. Effects of phlebotomy on urinary porphyrin pattern and liver histology in patients with porphyria cutanea tarda. Am J Med Sci. 1983;285(1):2-12.

33. Hamid S, Cruz PD Jr, Lee WM. Urticarial vasculitis caused by hepatitis C virus infection: response to interferon alfa therapy. J Am Acad Dermatol. 1998;39(2 Pt 1):278-280.

34. David WS1, Peine C, Schlesinger P, Smith SA. Nonsystemic vasculitic mononeuropathy multiplex, cryoglobulinemia, and hepatitis C. Muscle Nerve. 1996;19(12):1596-1602. doi: 10.1002/(SICI)10974598(199612)19:12\&lt;1596::AID-MUS9\&gt;3.0.CO;2-5

35. Pilli M, Penna A, Zerbini A, Vescovi P, Manfredi M, Negro F, et al. Oral lichen planus pathogenesis: A role for the HCV-specific cellular immune response. Hepatology. 2002;36(6):1446-1452. doi: 10.1053/ jhep.2002.37199

36. Gumber SC, Chopra S. Hepatitis C: a multifaceted disease. Review of extrahepatic manifestations. Ann Intern Med. 1995;123(8):615-620.

37. Abdallah MA, Ghozzi MY, Monib HA, Hafez AM, Hiatt KM, Smoller BR, et al. Necrolytic acral erythema: a cutaneous sign of hepatitis $C$ virus infection. J Am Acad Dermatol. 2005;53(2):247-5. doi: 10.1016/j. jaad.2005.04.049

38. Khanna VJ, Shieh S, Benjamin J, Somach S, Zaim MT, Dorner W Jr, et al. Necrolytic acral erythema associated with hepatitis C: effective treatment with interferon alfa and zinc. Arch Dermatol. 2000;136(6):755-757.

39. Abdallah MA, Hull C, Horn TD. Necrolytic acral erythema: a patient from the United States successfully treated with oral zinc. Arch Dermatol. 2005;141(1):85-87. doi:10.1001/archderm.141.1.85

40. Hivnor CM, Yan AC, Junkins-Hopkins JM, Honig PJ. Necrolytic acral erythema: response to combination therapy with interferon and ribavirin. J AM Acad Dermatol. 2004;50(5):121-124. doi: 10.1016/j. jaad.2003.09.017

41.EL-Ghandour TM, Sakr MA, El-Sebai H, El-Gammal TF, El-Sayed MH. Necrolytic acral erythema in Egyptian patients with hepatitis C virus infection. J Gastroenterol Hepatol. 2006;21(7):1200-1206. doi: 10.1111/j.1440-1746.2006.04316.x 